\title{
Geopolymers Based on Mechanically Activated Fly Ash Blended with Dolomite
}

\author{
Alexander M. Kalinkin ${ }^{1, *(D)}$, Basya I. Gurevich ${ }^{1}$, Elena V. Kalinkina ${ }^{1}$, Mikhail V. Chislov ${ }^{2}$ (D) \\ and Irina A. Zvereva ${ }^{2}$ (D) \\ 1 Tananaev Institute of Chemistry-Subdivision of the Federal Research Centre, Kola Science Centre of the \\ Russian Academy of Sciences, Akademgorodok 26a, 184209 Apatity, Murmansk Region, Russia; \\ gurevich1931@yandex.ru (B.I.G.); e.kalinkina@ksc.ru (E.V.K.) \\ 2 Centre for Thermogravimetric and Calorimetric Research, Saint Petersburg State University, Universitetskaya \\ nab.7/9, 199034 St. Petersburg, Russia; mikhail.chislov@spbu.ru (M.V.C.); irina.zvereva@spbu.ru (I.A.Z.) \\ * Correspondence: a.kalinkin@ksc.ru; Tel.: +7-815-557-9523
}

Citation: Kalinkin, A.M.; Gurevich, B.I.; Kalinkina, E.V.; Chislov, M.V.;

Zvereva, I.A. Geopolymers Based on Mechanically Activated Fly Ash Blended with Dolomite. Minerals 2021, 11, 700. https://doi.org/ $10.3390 / \min 11070700$

Academic Editor: Thomas

N. Kerestedjian

Received: 21 May 2021

Accepted: 25 June 2021

Published: 29 June 2021

Publisher's Note: MDPI stays neutral with regard to jurisdictional claims in published maps and institutional affiliations.

Copyright: (c) 2021 by the authors. Licensee MDPI, Basel, Switzerland. This article is an open access article distributed under the terms and conditions of the Creative Commons Attribution (CC BY) license (https:// creativecommons.org/licenses/by/ $4.0 /)$.

\begin{abstract}
This study reports the effect of natural dolomite addition to fly ash and the mechanical activation of this blend on the geopolymerization process. Dolomite was replaced with fly ash at 1,3 , 5 , and $10 \mathrm{wt} . \%$. Geopolymers were synthesized at ambient temperature using $\mathrm{NaOH}$ solution as an alkaline agent. The geopolymerization process, reactivity of the raw material, compressive strength, and microstructure were studied using X-ray diffraction, Fourier-transform infrared spectroscopy, thermogravimetry, and scanning electron microscopy. It was shown that blending fly ash with dolomite and mechanical activation improved the geopolymer strength, especially during the early age of curing. For geopolymers prepared using a $90 \%$ fly ash $+10 \%$ dolomite blend cured for $7 \mathrm{~d}$, the strengths were 8.2-, 2.3-, and 1.4-fold higher than those for geopolymers prepared using $100 \%$ FA for $30 \mathrm{~s}, 180 \mathrm{~s}$, and $400 \mathrm{~s}$ milling times, respectively. A simple method for evaluating the increments of mechanical activation, carbonate additives, and the synergistic effect in the increase in the compressive strength of the composite geopolymer is proposed.
\end{abstract}

Keywords: fly ash; natural dolomite; mechanical activation; geopolymers

\section{Introduction}

Man-made deposits of coal ash (fly ash and bottom ash), a solid by-product of coal combustion, are found in the majority of thermal power stations and many industrial plants. The total annual production of coal ash worldwide, mainly fly ash (FA), is about 700 to 800 million tons, of which less than one-third is recycled [1,2]. The accumulated FA has become a problem for the environment because of its heavy metal content, which can be leached out [3,4]. The mineral composition of FA is mainly represented by the glass phase and also by quartz, mullite, magnetite, and other minerals. In the last two decades, intensive studies have been carried out on the use of FA for the preparation of geopolymer materials. Geopolymers are a subclass of alkali-activated materials synthesized by the reaction of low-calcium, natural or industrially produced aluminosilicate raw materials with an alkaline agent (for example, alkali metal hydroxide solution or a mixture of this solution with water glass) at temperatures close to ambient temperature [5-8]. Due to their energy savings, environmentally friendly processing, and high physicalmechanical properties, geopolymers are gaining attention in the construction industry as a potential replacement for Portland cement. In addition, geopolymers possess a complex of valuable physicochemical properties, and thus, based on these materials, it is possible to create environmentally friendly materials for fire and heat protection, wastewater treatment, matrices for the immobilization of heavy metals, and radioactive waste, among others [9-13]. 
Lee and van Deventer [14] showed that small additions of laboratory-grade synthetic calcium and magnesium carbonate salts $\left(\mathrm{CaCO}_{3}\right.$ and $\left.\mathrm{MgCO}_{3}\right)$ to a paste based on alkaliactivated fly ash resulted in an increase in the compressive strength of the geopolymer. Later, this conclusion was confirmed by studies of geopolymer composites involving widespread natural carbonate minerals, such as calcite and dolomite [15-26]. The positive effect of the addition of carbonate minerals on the physical-mechanical properties of geopolymer materials was explained mainly by the common filler effect. At the same time, it was also noted that calcite and dolomite were not completely chemically inert components. Due to partial dissolution, the carbonate minerals had an effect on the release of $\mathrm{Al}$ and $\mathrm{Si}$ from aluminosilicate raw materials (metakaolin or FA) and on the formation of alkaline activation products $[17,20,22,23]$. In addition, even $100 \%$ limestone $[20,27]$ and dolomite [28], alkali-activated by water glass, exhibited binding properties. This could be explained by (i) the gelation and drying of sodium silicate solution containing a small amount of dissolved $\mathrm{CaCO}_{3}[20,28]$ or (ii) formation of an intermixed calcium silicate gel (C-S-H), sodium and calcium silicate gel ( $\mathrm{N}-\mathrm{C}-\mathrm{S}-\mathrm{H})$, and sodium silicate gel $(\mathrm{N}-\mathrm{S}-\mathrm{H})$ [27]. The latter explanation is more likely because of the higher alkali content in the paste and the increased curing temperature.

Another approach that is used to improve the performance of the FA-based geopolymers is the mechanical activation (MA) of FA in mills [29-35]. Here, the terms "mechanical activation" (MA) and "milling" refer to the same process of mechanical treatment of a solid material. It is known that the geopolymer strength and related properties depend on the degree of conversion of the aluminosilicate raw material to the reaction product-sodiumcontaining aluminosilicate hydrogel (N-A-S-H gel) [36]. The rate of geopolymer synthesis is largely determined by its first stage-destruction/dissolution of the raw material by an alkaline agent. The two key factors that generally determine the rate of a heterogeneous process between substances in the solid and liquid state are (i) the specific surface area of the solid reagent and (ii) the reactivity of the solid reagent with respect to the liquid one. Importantly, mechanical treatment of FA in mills leads not only to a decrease in particle size (and increase in surface area), mainly in the initial stage of milling, but also an increase in FA reactivity compared with that of alkaline agent per unit surface area [33]. The increase in FA reactivity is explained by an increase in the amount of the amorphous (glass) phase and the generation of defects on the surface and in the bulk of the FA particles (deformation and weakening of bonds, increase in the lattice strain of mullite and quartz present in the FA, etc.) [37].

In recent work [38], the geopolymerization of FA blended with natural calcite using MA of the raw materials was studied. It demonstrated that blending of the FA with calcite (up to $10 \mathrm{wt} . \%$ ) and the MA of the blend resulted in a synergistic effect with respect to the geopolymer strength. The addition of calcite to FA and the MA of this mixture in a planetary mill was found to significantly improve the compressive strength of the geopolymers, especially at an early age. In this study, we focused on the effect of natural dolomite addition to the same FA using the same experimental scheme [38]. The dolomite content in the mixtures was $0,1,3,5$, and $10 \mathrm{wt} . \%$. The influence of dolomite dosage and milling time on the reactivity of the raw material in relation to $\mathrm{NaOH}$ solution and on the geopolymer microstructure and compressive strength was studied. Increments of MA, carbonate additive, and the synergistic effect in the composite geopolymers' strength were isolated to explain the obtained experimental data.

\section{Materials and Methods}

\subsection{Materials}

Low-calcium FA (Class F) was sampled from the Apatity thermal power plant (Murmansk region, Russia). Quartz and mullite were the main crystalline phases in the FA (Figure 1). Natural dolomite was taken from the Titan deposit, Murmansk Region, Russia. About $4-5 \%$ of quartz and a minor amount of calcite were present in dolomite as admix- 
tures (Figure 1). The dolomite was milled in a ball mill and sieved using $300 \mu \mathrm{m}$ mesh.

Table 1 shows the chemical compositions of the FA and dolomite.

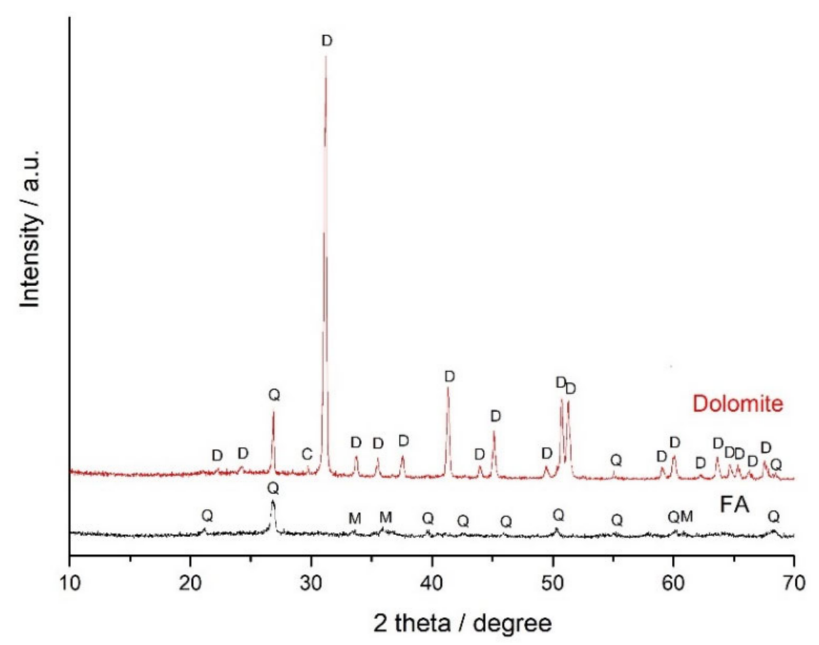

Figure 1. The XRD patterns of the FA and natural dolomite. Phases marked are D-dolomite (ICDD 00-036-0426), Q-quartz (ICDD 00-046-1045), M-mullite (ICDD 00-015-0776), and C—calcite (ICDD 00-005-0586).

Table 1. Chemical compositions of the FA and dolomite, wt.\%. (n/a-not analyzed).

\begin{tabular}{cccccccccccccc}
\hline Raw Materials & $\mathrm{SiO}_{2}$ & $\mathrm{Al}_{2} \mathbf{O}_{\mathbf{3}}$ & $\mathbf{F e}_{2} \mathbf{O}_{\mathbf{3}}$ & $\mathbf{F e O}$ & $\mathbf{C a O}$ & $\mathbf{M g O}$ & $\mathbf{S O}_{3}$ & $\mathbf{N a}_{2} \mathbf{O}$ & $\mathbf{K}_{\mathbf{2}} \mathbf{O}$ & $\mathbf{C}$ & $\mathbf{P}_{2} \mathbf{O}_{5}$ & $\mathrm{TiO}_{2}$ & $\mathbf{L O I}$ \\
\hline FA & 56.26 & 18.39 & 8.58 & 0.69 & 2.14 & 2.60 & 0.18 & 4.04 & 1.32 & 0.88 & 0.32 & 1.13 & 2.28 \\
Dolomite & 4.76 & 0.18 & 0.23 & n/a & 30.66 & 21.96 & 0.01 & 0.12 & 0.09 & n/a & n/a & n/a & 44.35 \\
\hline
\end{tabular}

\subsection{Mechanical Activation}

MA was carried out in an AGO-2 laboratory planetary mill (Novic, Novosibirsk, Russia) in air at a centrifugal force of $40 \mathrm{~g}$. Steel vials and steel balls $8 \mathrm{~mm}$ in diameter were used as the milling bodies. The details of MA are described in [38].

\subsection{Synthesis of Geopolymers}

The synthesis of geopolymers was carried out according to a methodology similar to that used in the previous work [38]. Sodium hydroxide solution ( $8.3 \mathrm{M})$ was used as the alkaline agent. The mass ratio of $\mathrm{Na}_{2} \mathrm{O}$ (present in the $\mathrm{NaOH}$ solution) to the mechanically activated FA + dolomite mixtures in the paste was equal to 0.06 . The water content was adjusted to ensure the same workability of the pastes, so the water content varied. The water to solid ratio $(\mathrm{w} / \mathrm{s})$ was determined taking into account the amount of water present in the $\mathrm{NaOH}$ solution. Table 2 shows the composition of the blends used for the preparation of the pastes. The unreacted FA + dolomite blends are denoted as FAXDY, where $\mathrm{X}$ is the dolomite content in the blend (wt.\%) and $\mathrm{Y}$ is the MA time of the blend (s). The geopolymers, synthesized using the FAXDY blend, are referred to as GFAXDY.

Table 2. Composition of blends used for preparation of pastes.

\begin{tabular}{cccccc}
\hline $\begin{array}{c}\text { Blend } \\
\text { Code }\end{array}$ & $\begin{array}{c}\text { FA } \\
\text { (wt.\%) }\end{array}$ & $\begin{array}{c}\text { Dolomite } \\
\text { (wt.\%) }\end{array}$ & $\begin{array}{c}\text { w/s Ratio } \\
\text { (30 s MA) }\end{array}$ & $\begin{array}{c}\text { w/s Ratio } \\
\text { (180 s MA) }\end{array}$ & $\begin{array}{c}\text { w/s Ratio } \\
\text { (400 s MA) }\end{array}$ \\
\hline FA0D & 100 & 0 & 0.23 & 0.25 & 0.28 \\
FA1D & 99 & 1 & 0.23 & 0.23 & 0.25 \\
FA3D & 97 & 3 & 0.24 & 0.24 & 0.25 \\
FA5D & 95 & 5 & 0.25 & 0.25 & 0.25 \\
FA10D & 90 & 10 & 0.25 & 0.25 & 0.26 \\
\hline
\end{tabular}


The pastes were cast into $1.41 \mathrm{~cm} \times 1.41 \mathrm{~cm} \times 1.41 \mathrm{~cm}$ molds. As with the geopolymers based on the FA + calcite blends [38], specimens were cured in a relative humidity of $95 \pm 5 \%$ at $22 \pm 2{ }^{\circ} \mathrm{C}$ for $24 \mathrm{~h}$. After demolding, the specimens were further cured until testing time in the same conditions that were applied in the first $24 \mathrm{~h}$. Compressive strength data was obtained from an average of 3 samples after 7, 28, 180, and 360 days.

\subsection{Characterization Methods}

The specific surface area of the powders was measured using the nitrogen BET method with a Flow-Sorb II 2300 instrument (Micromeritics). Powder X-ray diffraction (XRD) patterns were recorded on a Shimadzu XRD-6000 instrument using $\mathrm{Cu}-\mathrm{K} \alpha$ radiation. Scanning was carried out in a range of $10-70^{\circ} 2 \theta$ with a step of 0.02 and a 1-s time of retention per step. Fourier-transform infrared (FTIR) spectra were recorded with a Nicolet 6700 FTIR spectrometer using potassium bromide tablets. Thermogravimetric (TG) analysis was performed on a Netzsch STA 449 F3 Jupiter instrument (NETZSCH, Selb, Germany) at a heating rate of $20^{\circ} \mathrm{C} / \mathrm{min}$ under $\mathrm{Ar}$ atmosphere in platinum crucibles. Geopolymer microstructure and morphology were studied using an LEO 420 scanning electron microscope (Zeiss) operated at $10 \mathrm{kV}$ after gold coating of the fractured surface. Elemental analysis was conducted with an INCA Energy 400 energy dispersive spectrometer (EDS) for X-ray microanalysis (Oxford Instruments) at the same voltage.

\section{Results and Discussion}

\subsection{Effect of Mechanical Activation on the FA + Dolomite Blends}

The BET-specific surface area (SSA) of the initial FA was $2.5 \pm 0.1 \mathrm{~m}^{2} \cdot \mathrm{g}^{-1}$. MA of the FA + dolomite blends for 30-400 s resulted in a continuous increase in the surface area. With a fixed duration of milling, the dolomite content in the blend slightly affected the SSA of the blend. The SSA of the FA + dolomite blends milled for 30,180, and $400 \mathrm{~s}$ were $2.9 \pm 0.1,5.3 \pm 0.2$, and $6.5 \pm 0.3 \mathrm{~m}^{2} \cdot \mathrm{g}^{-1}$, respectively.

Representative XRD patterns of the FA10D30 and FA10D180 mixtures are shown in Figure 2. It is clearly seen from the comparison of the peak intensities that in dolomite, the disorder of the mineral lattice and/or the decrease in crystallite size induced by milling were considerably more pronounced than those in mullite and quartz, which were present in the FA. This was due to the difference in the hardness of the minerals. The hardness on the Mohs scale for quartz, mullite, and dolomite is $7,6.3-7.5$, and 3.5-4.0, respectively [39,40].

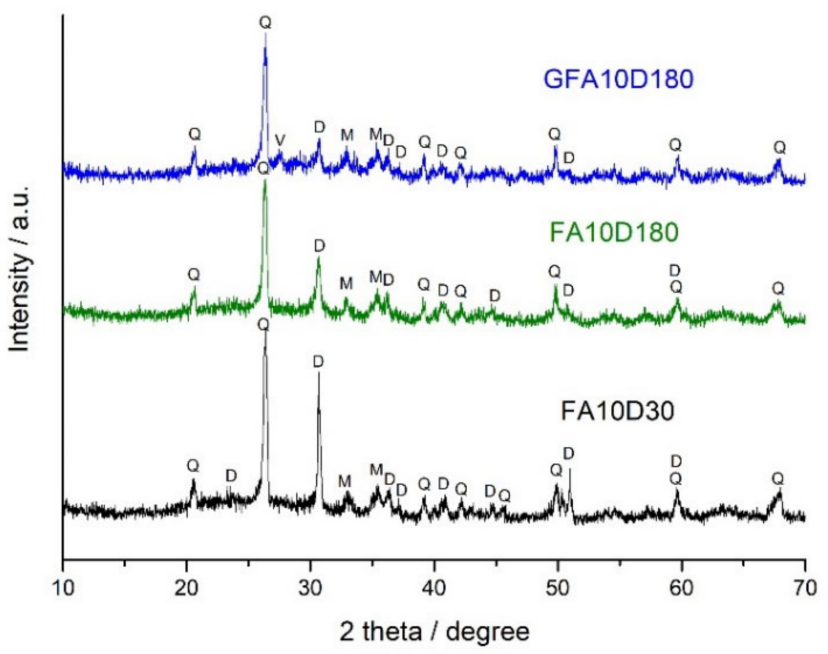

Figure 2. The XRD patterns of the $90 \% \mathrm{FA}+10 \%$ dolomite blend milled for $30 \mathrm{~s}$ and $180 \mathrm{~s}$ (FA10D30 and FA10D180, respectively) and of the geopolymer synthesized using the FA10D180 blend after $360 \mathrm{~d}$ of curing (GFA10B180). Phases marked are Q- quartz (ICDD 00-046-1045), M-mullite (ICDD 00-015-0776), D—dolomite (ICDD 00-036-0426), and V-vaterite (ICDD 00-033-0268). 


\subsection{Mechanical Properties}

Figure 3 shows the compressive strength of geopolymers measured after 7, 28, 180, and 360 days of curing. As in the case of FA + calcite mixtures [38], the blending of the FA with dolomite generally resulted in an increase in compressive strength with an increase in the proportion of the added carbonate mineral. The positive effect of adding dolomite to the FA was more pronounced for the early age of curing. For example, the geopolymers prepared using the blend containing 90\% FA and 10\% dolomite (GFA10D30, GFA10D180, and GFA10D400) cured for $7 \mathrm{~d}$ showed strengths 8.2-, 2.3-, and 1.4-fold higher than the strengths of the geopolymers of the same age based on 100\% FA (GFA0D30, GFA0D180, and GFA0D400, respectively) (Figure 3a). For the same pairs of geopolymers cured for $360 \mathrm{~d}$, the corresponding strengths increased by 1.5-, 1.2-, and 1.1-fold, respectively (Figure 3d).

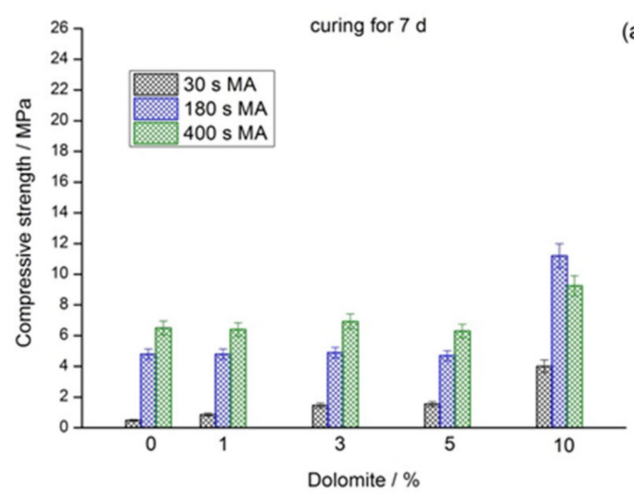

(a)
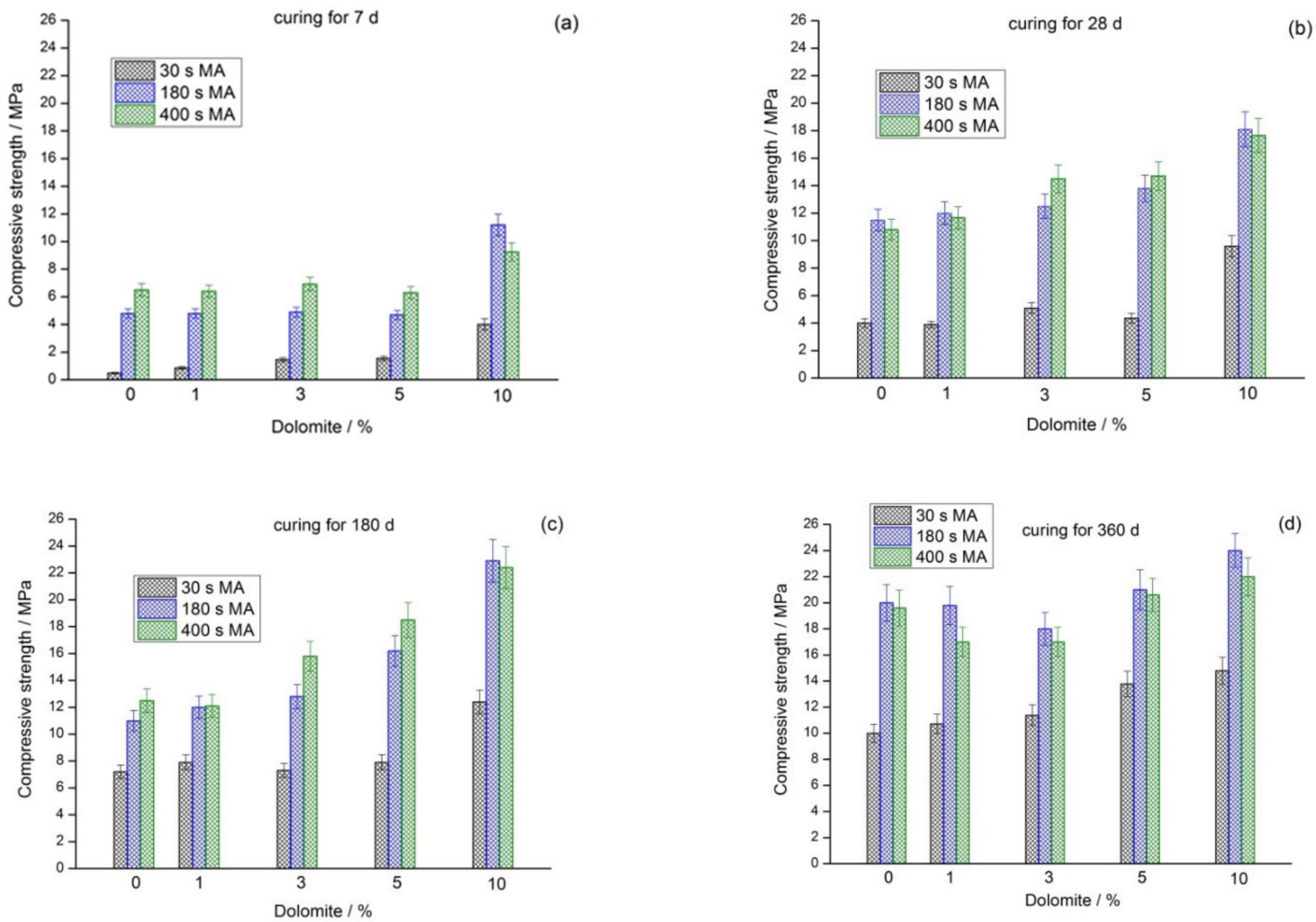

Figure 3. Effect of dolomite content and MA time on the compressive strength of geopolymers cured for 7 (a), 28 (b), 180 (c), and 360 (d) days.

In agreement with the SSA of the FA + dolomite blends, MA for $180 \mathrm{~s}$, compared with MA for $30 \mathrm{~s}$, led to a significant increase in compressive strength. The effect of further MA from 180 to $400 \mathrm{~s}$ was either very slightly positive or unfavorable (Figure 3a-d). However, as expected, the finer FA showed better solubility in the $\mathrm{NaOH}$ solution to produce a higher amount of geopolymer gel and, therefore, a higher compressive strength. A similar effect of "over-grinding" on strength was observed for geopolymers prepared using FA + calcite blends [38]. This can be explained by the optimal particle size distribution, which is another key factor affecting the geopolymer strength [41].

When comparing the addition of calcite or dolomite to the FA, it should be noted that calcite is preferable in terms of the strength of geopolymers. For the FA + calcite blends containing $1,3,5$, and $10 \%$ calcite milled for $180 \mathrm{~s}$, the compressive strengths of the geopolymers cured for $7 \mathrm{~d}$ were $7.4,11.2,13.0$, and $16.8 \mathrm{MPa}$, respectively [38]. For the FA + dolomite blends, the corresponding strengths were 4.8, 4.9, 4.7, and $11.2 \mathrm{MPa}$, respectively (Figure 3a). With an increase in curing time, the difference in the strength of geopolymers prepared using calcite and dolomite decreased. For the FA + calcite blends containing 1, 3, 
5 , and $10 \%$ calcite milled for $180 \mathrm{~s}$, the compressive strengths of the geopolymers cured for $28 \mathrm{~d}$ were 12.7, 16.6, 19.5, and 22.4 MPa, respectively [38]. For the FA + dolomite blends, the corresponding strengths were 12.0, 12.5, 13.8, and 18.1 MPa, respectively (Figure 3b).

Similar results were obtained by Yip et al. [20], who studied the synthesis of geopolymers based on metakaolin with additions of $20 \%$ calcite or $20 \%$ dolomite using sodium metasilicate solutions as alkaline agents (without the use of MA of the raw materials). The more favorable effect of calcite addition to metakaolin compared with dolomite addition was explained by (i) a higher dissolved calcium level, which may affect the geopolymer gel structure, and (ii) differences in surface characteristics of calcite and dolomite, which may influence surface binding of the unreacted carbonate minerals to the geopolymer gel [20].

It was of interest to separate the increments of MA and carbonate (dolomite or calcite) addition in the increase in the compressive strength of the geopolymers and to estimate the synergistic effect of simultaneous blending of the FA with the carbonate and milling. To this end, for each curing period, we used the strength of the geopolymer based on 100\% FA mechanically activated for $30 \mathrm{~s}$ (G0D30) as a reference point. It can be conditionally assumed that the increment of MA and carbonate additions in the strength of the G0D30 geopolymer is equal to 0 .

Let us introduce the following notations:

$\mathrm{R}\left(\mathrm{GXDY}\right.$ - - strength of the GXDY geopolymer at a certain age, $\mathrm{MPa} \mathrm{R}_{\mathrm{o}}=\mathrm{R}(\mathrm{G} 0 \mathrm{D} 30)$ strength of the G0D30 geopolymer at a certain age (reference point), $\mathrm{MPa}$

$\mathrm{R}_{\mathrm{MA}}$-increment of MA in the geopolymer strength, $\mathrm{MPa}$

$\mathrm{R}^{\text {rel }} \mathrm{MA}$-relative increment of MA in the geopolymer strength, \%

$\mathrm{R}_{\mathrm{C}}$-increment of carbonate addition in the geopolymer strength, $\mathrm{MPa}$

$\mathrm{R}^{\mathrm{rel}} \mathrm{C}$-relative increment of carbonate addition in the geopolymer strength, \%

$\mathrm{R}_{\mathrm{SE}}$ - increment of the synergistic effect in the geopolymer strength, $\mathrm{MPa}$

The increment of MA in the strength of GXDY geopolymer (based on a blend mechanically activated for $Y$ seconds) can be estimated as $R_{M A}(G X D Y)=R(G 0 D Y)-R_{0}$, i.e., the difference between the strengths of geopolymers based on 100\% FA milled for Y s and those milled for $30 \mathrm{~s}$ for the same hardening period. In particular, the increment of MA in the strength of all geopolymers based on the FA + dolomite blends mechanically activated for $180 \mathrm{~s}(\mathrm{GXD180})$ is equal to $R_{M A}(G X D 180)=R(G 0 D 180)-R_{O}$. The relative increment of MA in the strength of the GXDY geopolymer is defined as $\mathrm{R}^{\mathrm{rel}} \mathrm{MA}(\mathrm{GXDY})=$ $\left(\mathrm{R}_{\mathrm{MA}}(\mathrm{GXDY}) / \mathrm{R}(\mathrm{G} 0 \mathrm{DY})\right) \cdot 100 \%$.

The increment of carbonate addition in the strength of the GXDY geopolymer $\left(\mathrm{R}_{\mathrm{C}}\right)$ was determined from the strength of geopolymers based on the FA + dolomite blends with zero MA increment, i.e., milled for $30 \mathrm{~s}$. For example, the increment of carbonate addition in the strength of G5D180 or G5D400 geopolymers at the age of 7 days is $\mathrm{R}_{\mathrm{C}}(\mathrm{G} 5 \mathrm{D} 180)=$ $R_{C}(G 5 D 400)=R(G 5 D 30)-R(G 0 D 30)$, where $R(G 5 D 30)$ and $R(G 0 D 30)$ are the strengths of the geopolymers after 7 days of hardening. In general, $R_{C}(G X D Y)=R(G X D 30)-R(G 0 D 30)$. The relative increment of carbonate addition in the strength of the GXDY geopolymer is $\mathrm{R}^{\mathrm{rel}}{ }_{\mathrm{C}}(\mathrm{GXDY})=\left(\mathrm{R}_{\mathrm{C}}(\mathrm{GXDY}) / \mathrm{R}(\mathrm{GXD30})\right) \cdot 100 \%$.

Taking into account the introduced designations, the strength of GXDY geopolymer (R) at a certain age can be represented by the following equation:

$$
\mathrm{R}=\mathrm{R}_{\mathrm{O}}+\mathrm{R}_{\mathrm{MA}}+\mathrm{R}_{\mathrm{C}}+\mathrm{R}_{\mathrm{SE}}
$$

where $R_{S E}$ is the increment in strength due to the synergistic effect of MA and carbonate addition. It should be noted that in Equation (1), all values refer to the same geopolymer curing time. Having calculated the $R_{M A}$ and $R_{C}$ from the strength data (Figure 3 ), using Equation (1), it is possible to estimate the $R_{S E}$ value for the FA + dolomite blend. Using the experimental data given in [38], one can similarly evaluate the corresponding increments in the strength of geopolymers based on the FA + calcite blend.

Figure 4 shows the relative increment of MA in the strength of geopolymers at the age of 7 and 28 days. The $\mathrm{R}^{\text {rel }}$ MA value in the early hardening period (7 days) was noticeably 
higher compared with that of the geopolymers aged for 28 days. Apparently, this is due to the fact that in the initial stage, the most reactive fine FA particles preferentially interacted with the alkaline agent to form an aluminosilicate hydrogel.

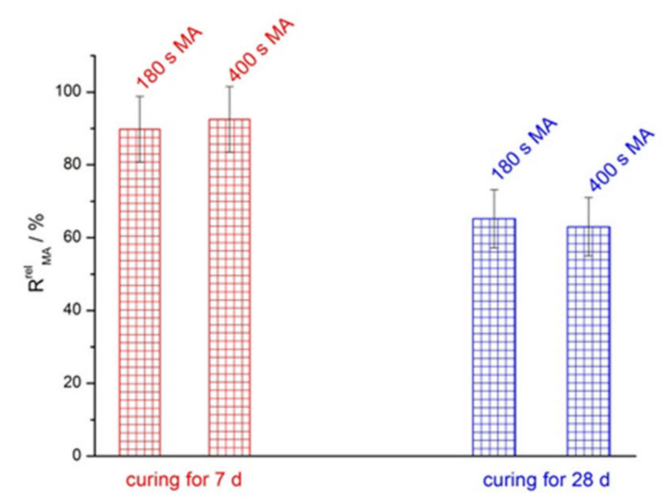

Figure 4. Relative increment of MA in the strength of geopolymers $\left(\mathrm{R}^{\mathrm{rel}} \mathrm{MA}\right)$ at the age of 7 and 28 days.

Subsequently, the intensity of this interaction decreased, which led to a decrease in strength development. For both periods of hardening, the relative increment of MA for $180 \mathrm{~s}$ and $400 \mathrm{~s}$ was approximately the same (Figure 4), which may be due to the effect of the "over-grinding" mentioned above. As follows from the $\mathrm{R}^{\text {rel }} \mathrm{MA}$ definition, this value does not depend on the type of additive to FA and is determined only by the milling parameters. Consequently, the data presented in Figure 4 also characterize the relative increment of MA in geopolymers based on the FA + calcite blend mechanically activated using the same MA scheme [38].

The relative increments of the carbonate mineral addition $\left(\mathrm{R}^{\mathrm{rel}} \mathrm{C}\right)$ in the strength of geopolymers based on the FA + dolomite and FA + calcite blends are shown in Figures 5 and 6, respectively. As with the MA increment (Figure 4), the addition of both carbonates was most noticeable at the age of 7 days. The addition of calcite was preferable to dolomite, although with an increase in the content of the carbonate additive, the difference in the relative contribution decreased. It should also be noted that for geopolymers with the addition of dolomite, $\mathrm{R}^{\mathrm{rel}} \mathrm{C}$ tended to continuously increase with increasing dolomite content (Figure 5).

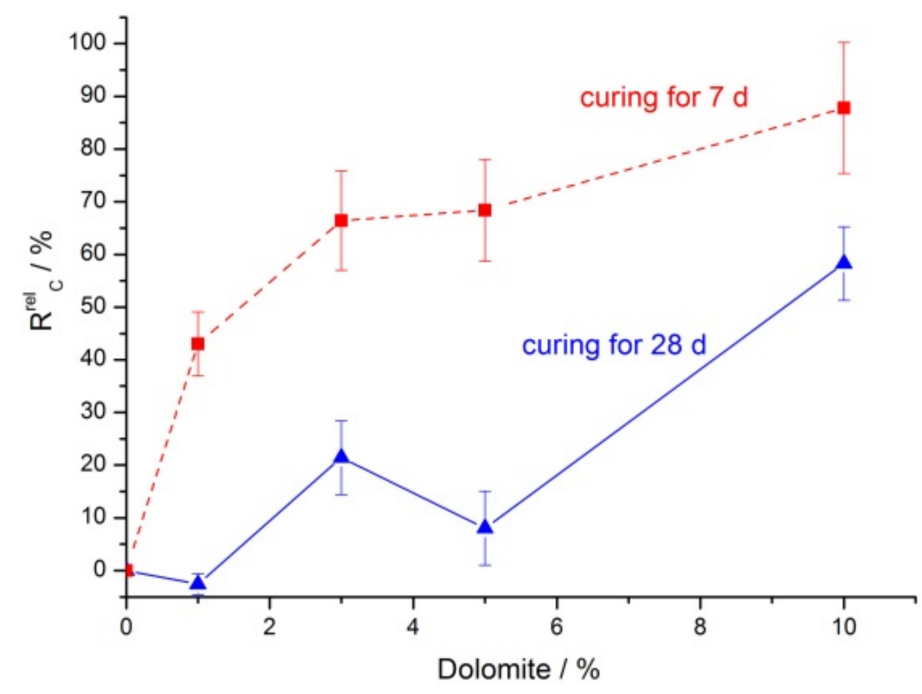

Figure 5. Relative increment of dolomite addition in the strength of geopolymers $\left(\mathrm{R}^{\mathrm{rel}} \mathrm{C}\right)$ based on the FA + dolomite blends at the age of 7 and 28 days. 


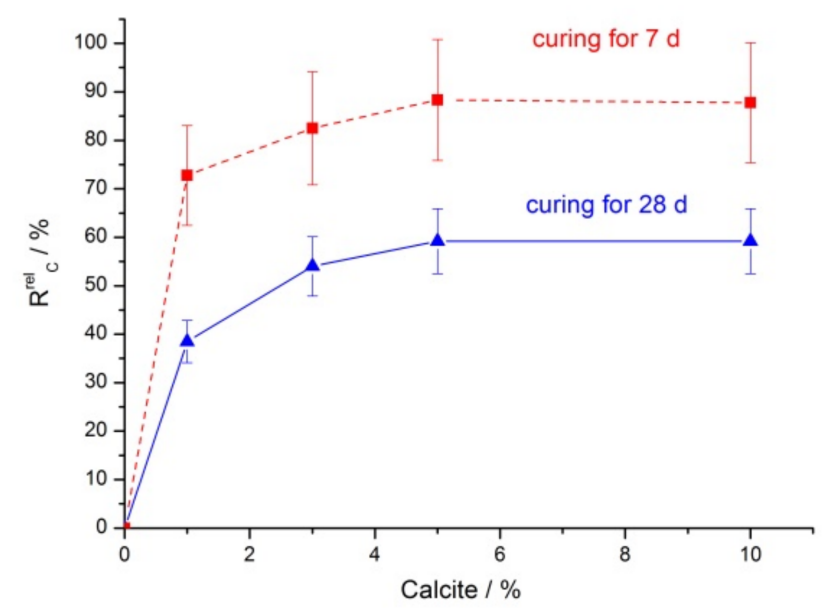

Figure 6. Relative increment of calcite addition in the strength of geopolymers $\left(\mathrm{R}^{\mathrm{rel}} \mathrm{C}\right)$ based on the FA + calcite blends at the age of 7 and 28 days (calculated using data from [38]).

In the case of calcite, after adding $5 \%$ of the carbonate mineral, the $\mathrm{R}^{\mathrm{rel}}{ }_{\mathrm{C}}$ reached a plateau (Figure 6). Most likely, these trends are explained by a combination of the two factors noted above: First, the physical filler/micro-aggregate effect, and second, the leaching of $\mathrm{Ca}^{2+}$ and $\mathrm{Mg}^{2+}$ ions from calcite and dolomite, which can affect the release of $\mathrm{Al}$ and $\mathrm{Si}$ ions from aluminosilicate raw materials and the formation of an aluminosilicate hydrogel $[20,22,23]$.

It is interesting to compare the increments of the synergistic effect on the strength of geopolymers $\left(\mathrm{R}_{\mathrm{SE}}\right)$ based on FA with added dolomite (Figure 7 ) and calcite (Figure 8). In general, in the geopolymers with dolomite added, the synergistic effect was less pronounced than that in the geopolymers with calcite added. For dolomite, this effect was almost independent of the amount of added carbonate and was mainly manifested at the age of 28 days. In the case of calcite, on the contrary, the effect was more noticeable in the early period of hardening ( 7 days), and there was a tendency for an increase in $R_{S E}$ with an increase in calcite content (Figure 8). The increase in $R_{S E}$ was especially noticeable with an increase in the calcite content from 5 to $10 \%$, the reason for which is discussed below in Section 3.4. An increase in the MA time from $180 \mathrm{~s}$ to $400 \mathrm{~s}$ did not explicitly affect the $\mathrm{R}_{\mathrm{SE}}$ values (Figures 7 and 8 ).

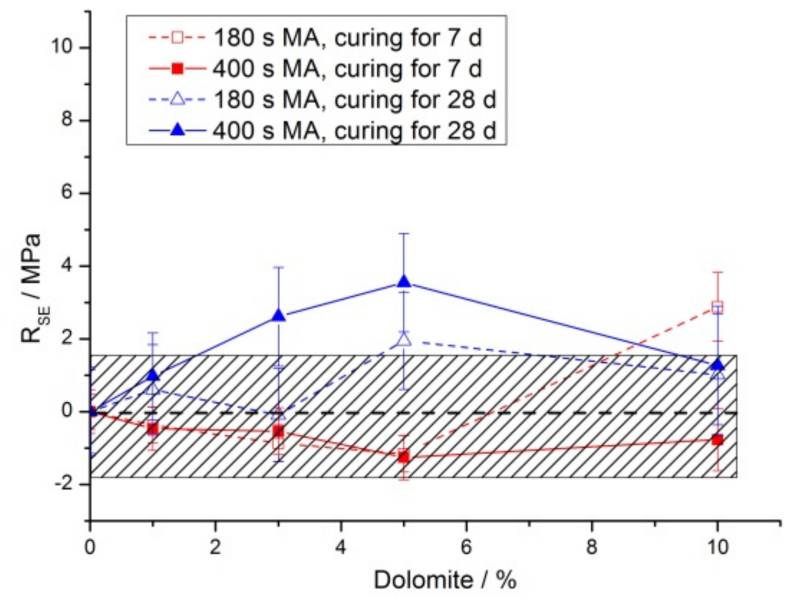

Figure 7. Increment of the synergistic effect $\left(\mathrm{R}_{\mathrm{SE}}\right)$ in the strength of geopolymers based on the FA + dolomite blends at the age of 7 and 28 days. The shaded area includes the data for which the $R_{\mathrm{SE}}$ is close to zero. 


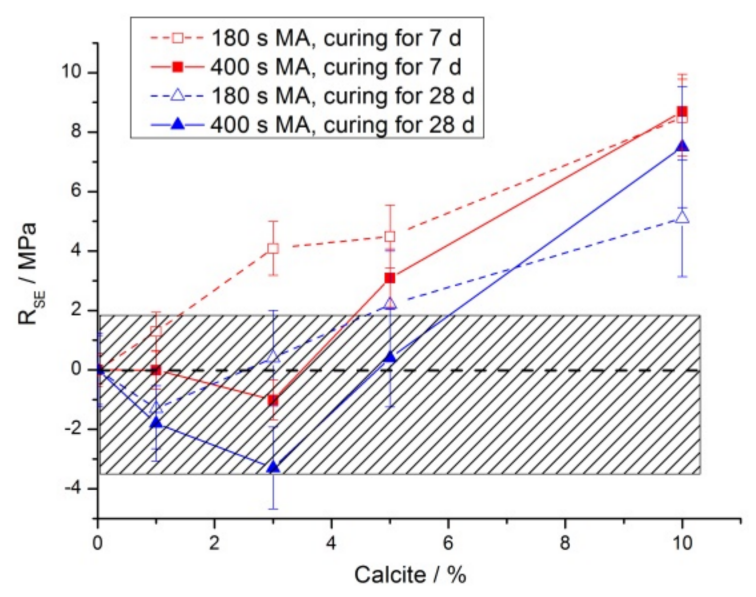

Figure 8. Increment of the synergistic effect $\left(\mathrm{R}_{\mathrm{SE}}\right)$ in the strength of geopolymers based on the FA + calcite blends at the age of 7 and 28 days (calculated using data from [38]). The shaded area includes the data for which the $\mathrm{R}_{\mathrm{SE}}$ is close to zero.

In Figure 9, as an example, the distribution of the increments of the terms on the right side of Equation (1) in the strength of geopolymers based on the mixtures of FA with $10 \%$ calcite or $10 \%$ dolomite, milled for $180 \mathrm{~s}$ at the age of 7 and 28 days, is presented. For geopolymers hardened for 7 days, the contribution of $R_{C}$ and $R_{S E}$ to the strength was significant; these values depend on the nature of the carbonate additive. At the age of 28 days, the proportion of the contribution to the strength of $R_{o}$ and $R_{M A}$, which for a given MA time and curing period are constant for both carbonate additives, was markedly higher compared with that at the age of 7 days. This explains the tendency noted above for a decrease in the difference in the strength of geopolymers prepared with additions of calcite and dolomite with an increase in the curing time.

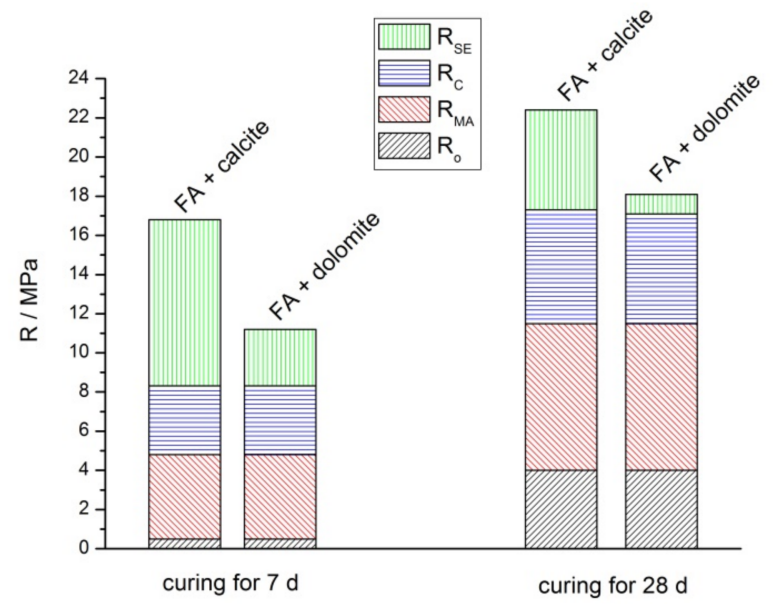

Figure 9. The increments of $R_{O}, R_{M A}, R_{C}$, and $R_{S E}$ in the strength of geopolymers based on the $90 \%$ FA $+10 \%$ calcite and $90 \%$ FA $+10 \%$ dolomite blends mechanically activated for $180 \mathrm{~s}$ at the age of 7 and 28 days.

\subsection{TG Analysis}

Figure 10 presents the TG data for the GFA1D30, GFA10D30, and GFA10D180 geopolymers cured for $360 \mathrm{~d}$. By comparing these with the geopolymers based on the mechanically activated FA + calcite blend [38], it is possible to distinguish three temperature ranges for the weight loss: (i) elimination of free and loosely bound water $\left(<120^{\circ} \mathrm{C}\right)$, (ii) removal of the water tightly bound with N-A-S-H gel $\left(120-500{ }^{\circ} \mathrm{C}\right.$ ), and (iii) decomposition of carbonates releasing $\mathrm{CO}_{2}\left(>500^{\circ} \mathrm{C}\right)$. 


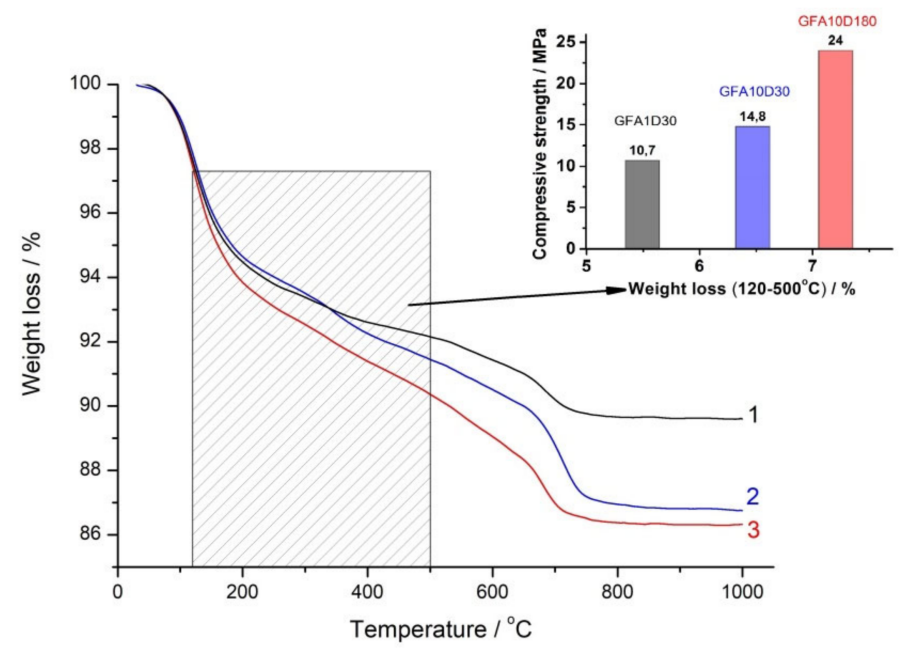

Figure 10. Thermogravimetric (TG) curves of the geopolymers based on the $1-(99 \% \mathrm{FA}+1 \%$ dolomite) blend milled for $30 \mathrm{~s}$ (GFA1D30), 2-(90\% FA $+10 \%$ dolomite) blend milled for $30 \mathrm{~s}$ (GFA10D30), and 3-(90\% FA + 10\% dolomite) blend milled for $180 \mathrm{~s}$ (GFA10D180). Curing time for all geopolymers was $360 \mathrm{~d}$. In the insert, the compressive strength of the geopolymers vs. the weight loss of the geopolymers in the $120-500{ }^{\circ} \mathrm{C}$ temperature range (shaded area) is shown.

The weight loss in the middle temperature range $\left(120-500{ }^{\circ} \mathrm{C}\right)$ can be considered a measure of geopolymer gel formation [38]. It can be clearly seen from the insert in Figure 10 that the increase of dolomite content (cf. GFA1D30 and GFA10D30) and MA time (cf. GFA10D30 and GFA10D180) resulted in an increased amount of N-A-S-H gel and a corresponding increase in strength.

\subsection{XRD and FTIR Spectroscopy Analysis}

Figure 2 shows the XRD pattern of the GFA10D180 geopolymer cured for $360 \mathrm{~d}$. The formation of a binder product, amorphous sodium-containing aluminosilicate hydrogel, was confirmed by the appearance of a halo in the $25-35^{\circ} 2 \theta$ region [42]. It should be noted that the main dolomite reflection, at approximately $2 \theta=30.8^{\circ}$ in the XRD pattern of the GFA10D180, slightly decreased in intensity compared with that of the FA10D180 blend (Figure 2). Along with this, the XRD pattern of the GFA10D180 showed a small peak, which can likely be attributed to a newly formed phase, vaterite, a calcium carbonate polymorph However, since the intensity of this peak is small and no other peaks of vaterite were found, this assumption requires additional research. The formation of vaterite was also revealed in geopolymers prepared using a mechanically activated mixture containing $90 \%$ FA and $10 \%$ calcite [38]. The transformation of calcite to vaterite can proceed through recrystallization in sodium hydroxide solution, according to the Ostwald step rule $[43,44]$. No newly formed crystalline phases were found in the geopolymers prepared using blends containing $5 \%$ or less dolomite.

FTIR spectra of the blend containing 10\% dolomite milled for $400 \mathrm{~s}$ (FA10D400), as well as the geopolymer prepared using this blend at the ages of 7 and $180 \mathrm{~d}$ (GFA10D400), are presented in Figure 11. The main absorption band at $1089 \mathrm{~cm}^{-1}$ was due to the $\mathrm{Si}-$ $\mathrm{O}-\mathrm{T}(\mathrm{T}=\mathrm{Si}, \mathrm{Al})$ asymmetric stretching vibrations. The IR peaks in the $800-600 \mathrm{~cm}^{-1}$ region correspond to the $\mathrm{Si}-\mathrm{O}-\mathrm{T}(\mathrm{T}=\mathrm{Si}, \mathrm{Al})$ symmetric stretching vibrations and are associated with the presence of quartz and mullite in the FA [45-47]. The broad band in the $3700-3100 \mathrm{~cm}^{-1}$ region (O-H stretching vibration) in the spectrum of FA10D400 was due to the $\mathrm{H}_{2} \mathrm{O}$ adsorbed by the mixture from the air over the course of MA. The band at $1456 \mathrm{~cm}^{-1}$ corresponds to the asymmetric stretching vibrations of the carbonate group in dolomite [48]. 


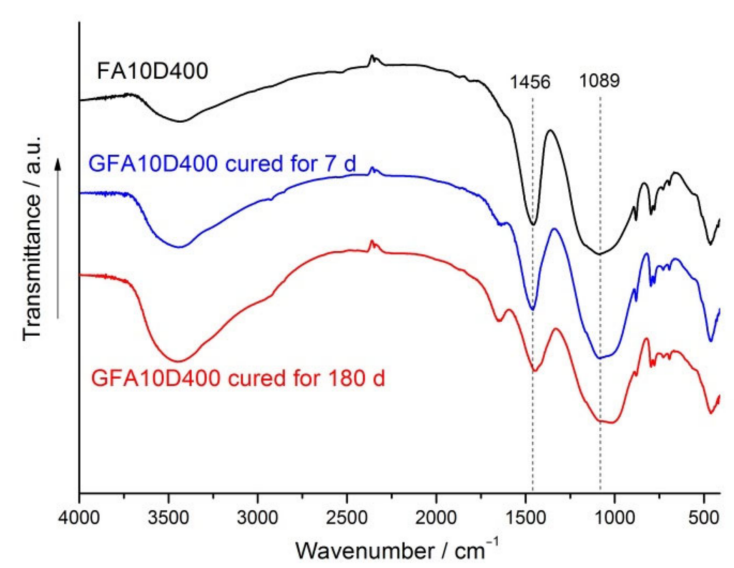

Figure 11. FTIR spectra of the $90 \%$ FA $+10 \%$ dolomite blend milled for $400 \mathrm{~s}$ (FA10D400) and the geopolymer based on this blend (GFA10D400) cured for 7 and $180 \mathrm{~d}$.

Changes in the IR spectra of geopolymers containing dolomite, in comparison with the spectra of the blends, were similar to the corresponding changes in the spectra of previously studied geopolymers based on FA with the addition of calcite [38]. The main peak associated with the $\mathrm{Si}-\mathrm{O}-\mathrm{T}$ asymmetric stretching vibrations in the spectra of the GFA10D400 geopolymer shifted toward a lower wavenumber in comparison with that of the unreacted blend (Figure 11). This indicates the formation of a binder product, $\mathrm{N}-\mathrm{A}-\mathrm{S}-\mathrm{H}$ gel, and can be explained by the substitution of silicon for aluminum in the $\mathrm{SiO}_{4}$ tetrahedra and a decrease in the degree of polymerization of the aluminosilicate framework of the FA.

The main peak of dolomite for GFA10D400 at $1456 \mathrm{~cm}^{-1}$ broadened and decreased in intensity in comparison with that for FA10D400 (Figure 11). In the IR spectrum of vaterite, the main peak was split $\left(1420\right.$ and $1490 \mathrm{~cm}^{-1}$ ) due to the reduced symmetry of the $\mathrm{CO}_{3}$ ion in the crystalline lattice of the mineral [48]. Therefore, the broadening of the main IR peak of dolomite indirectly confirms the XRD data (Figure 2) on the partial transformation of dolomite to vaterite.

\subsection{Microstructural Studies}

Figure 12 displays the microstructures of selected geopolymer specimens prepared using the FA + dolomite blends mechanically activated for 30 and $180 \mathrm{~s}$ and cured for $360 \mathrm{~d}$. The geopolymers prepared using a blend containing 10\% dolomite milled for 180 and $30 \mathrm{~s}$ (GFA10D180 and GFA10D30) were characterized by compressive strengths of 24.0 and $14.8 \mathrm{MPa}$, respectively (Figure 3). In accordance with the strength data, the former geopolymer (Figure 12a) showed a more uniform dense microstructure in comparison with the latter (Figure 12b).

The geopolymer based on the 99\% FA + 1\% dolomite blend milled for $30 \mathrm{~s}$ (GFA1D30), which was characterized by a compressive strength of $10.8 \mathrm{MPa}$ (Figure 3), contained a noticeable amount of unreacted FA spherical particles and exhibited a more porous structure (Figure 12c) compared with the structure of the GFA10D180 and GFA10D30 geopolymers (Figure 12a,b, respectively).

In a previous study [38], for a geopolymer prepared using a $90 \% \mathrm{FA}+10 \%$ calcite blend mechanically activated for $180 \mathrm{~s}$, a partial transformation of calcite to $\mathrm{Ca}(\mathrm{OH})_{2}$ (portlandite) was observed by SEM/EDS. No calcium hydroxide was detected in geopolymers based on the FA + calcite blends containing less than 10\% calcite [38] or in any geopolymers based on the FA + dolomite blend studied in this work. The formation of portlandite likely occurred through the leaching of calcium from calcite into an alkali solution and subsequent crystallization. Therefore, the absence of calcium hydroxide as the newly formed phase in geopolymers is probably due to the lower concentration of $\mathrm{Ca}^{2+}$ ions in the liquid phase released from the carbonates. 

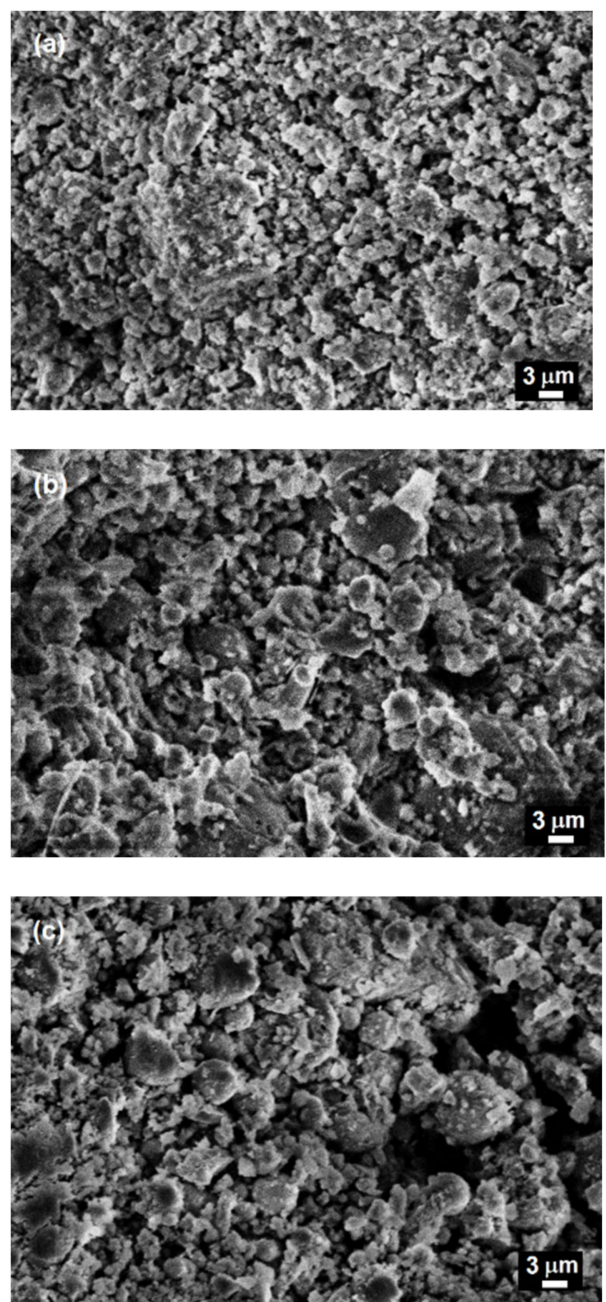

Figure 12. SEM images of the geopolymers cured for 360 d: GFA10D180 (a), GFA10D30 (b) and GFA1D30 (c).

Calcium hydroxide provides nucleation sites that enhance N-A-S-H gel formation $[49,50]$. In this regard, the increased concentration of calcium ions in the $\mathrm{NaOH}$ solution, leading to the precipitation of $\mathrm{Ca}(\mathrm{OH})_{2}$, is likely to be the cause of a significant increase in the increment of the synergistic effect in the strength of geopolymers based on the $90 \% \mathrm{FA}+10 \%$ calcite blend compared with the $\mathrm{R}_{\mathrm{SE}}$ of other geopolymers, as shown in Figure 8.

\section{Conclusions}

The room temperature-cured geopolymers were synthesized using the mechanically activated blends of FA and natural dolomite. The dolomite content in the blends was 0,1 , 3,5 , and $10 \mathrm{wt} . \%$. $\mathrm{NaOH}$ solution was used as an alkaline agent.

The milling of the blends in a planetary mill considerably enhanced their reactivity with respect to the sodium hydroxide solution, as observed using FTIR spectroscopy and SEM. Blending the FA with dolomite improved the geopolymer strength, especially at an early age of curing. For geopolymers prepared using the $90 \%$ FA $+10 \%$ dolomite mixture cured for $7 \mathrm{~d}$, the strengths were 8.2-, 2.3-, and 1.4-fold higher than those of the geopolymers prepared using $100 \%$ FA for $30 \mathrm{~s}, 180 \mathrm{~s}$, and $400 \mathrm{~s}$ milling time, respectively. The main geopolymerization product of the mechanically activated FA + dolomite mixtures was X-ray amorphous sodium-containing aluminosilicate hydrogel. For the geopolymers prepared using the mixture containing $10 \%$ dolomite, the partial transformation of dolomite 
to vaterite was revealed by $\mathrm{X}$-ray diffraction. Additional research is needed to identify new crystalline phases formed as a result of the geopolymerization reactions.

In terms of the geopolymer strength, the blending of FA with dolomite was less preferable than blending with calcite. For the FA + dolomite blends containing 1,3,5, and $10 \%$ dolomite milled for $180 \mathrm{~s}$, the compressive strengths of the geopolymers cured for $7 \mathrm{~d}$ were 4.8, 4.9, 4.7, and 11.2 MPa, respectively. For the FA + calcite blends, the corresponding strengths were $7.4,11.2,13.0$, and $16.8 \mathrm{MPa}$, respectively. With an increase in curing time, the differences in the strengths of geopolymers prepared using calcite and dolomite decreased. The revealed regularities were explained on the basis of a simple method that allowed the isolation of the increments of MA, carbonate additives, and the synergistic effect in the composite geopolymers strength. For geopolymers prepared using a dolomite additive, the synergistic effect was less pronounced than that of geopolymers based on the FA + calcite blends. This was likely due to the lower concentration of calcium ions leached from dolomite compared with that from calcite. In particular, a higher concentration of $\mathrm{Ca}^{2+}$ released from calcite may lead to precipitation of $\mathrm{Ca}(\mathrm{OH})_{2}$, thus providing nucleation sites for sodium-containing aluminosilicate hydrogel formation and increasing the development of the geopolymer strength.

Author Contributions: Conceptualization, A.M.K., B.I.G., and E.V.K.; methodology, A.M.K., B.I.G., M.V.C., E.V.K., and I.A.Z.; investigation, B.I.G., M.V.C., E.V.K., and I.A.Z.; writing-original draft preparation, A.M.K.; writing-review and editing, A.M.K., B.I.G., E.V.K., and I.A.Z.; visualization, A.M.K., E.V.K., and M.V.C. All authors have read and agreed to the published version of the manuscript.

Funding: The reported study was funded by RFBR, project number 20-03-00486.

Acknowledgments: The authors acknowledge support from the Centre for Thermogravimetric and Calorimetric Research of the Research Park of St. Petersburg State University, where the thermal analysis was performed. V.V. Semushin is acknowledged for his help in the SEM/EDS studies.

Conflicts of Interest: The authors declare no conflict of interest.

\section{References}

1. Yao, Z.; Ji, X.; Sarker, P.; Tang, J.; Ge, L.; Xia, M.; Xi, Y. A comprehensive review on the applications of coal fly ash. Earth-Sci. Rev. 2015, 141, 105-121. [CrossRef]

2. Jayaranjan, M.L.D.; Van Hullebusch, E.D.; Annachhatre, A.P. Reuse options for coal fired power plant bottom ash and fly ash. Rev. Environ. Sci. Bio/Technol. 2014, 13, 467-486. [CrossRef]

3. Wang, N.; Sun, X.; Zhao, Q.; Yang, Y.; Wang, P. Leachability and adverse effects of coal fly ash: A review. J. Hazard. Mater. 2020, 396, 122725. [CrossRef]

4. Singh, A.K.; Masto, R.E.; Hazra, B.; Esterle, J.; Singh, P.K. Ash from Coal and Biomass Combustion; Springer Science and Business Media LLC: Berlin/Heidelberg, Germany, 2020; pp. 91-114.

5. Provis, J.L. Alkali-activated materials. Cem. Concr. Res. 2018, 114, 40-48. [CrossRef]

6. Davidovits, J. Geopolymer Chemistry and Applications, 5th ed.; Institut Géopolymère: Saint-Quentin, France, 2020; pp. 23-208.

7. Krivenko, P. Why alkaline activation-60 years of the theory and practice of alkali-activated materials. J. Ceram. Sci. Technol. 2017, 8, 323-334. [CrossRef]

8. Singh, N.; Middendorf, B. Geopolymers as an alternative to Portland cement: An overview. Constr. Build. Mater. 2020, 237, 117455. [CrossRef]

9. Mehta, A.; Siddique, R. An overview of geopolymers derived from industrial by-products. Constr. Build. Mater. 2016, 127, 183-198. [CrossRef]

10. Tang, Z.; Li, W.; Hu, Y.; Zhou, J.L.; Tam, V.W. Review on designs and properties of multifunctional alkali-activated materials (AAMs). Constr. Build. Mater. 2019, 200, 474-489. [CrossRef]

11. Luukkonen, T.; Heponiemi, A.; Runtti, H.; Pesonen, J.; Yliniemi, J.; Lassi, U. Application of alkali-activated materials for water and wastewater treatment: A review. Rev. Environ. Sci. Bio/Technol. 2019, 18, 271-297. [CrossRef]

12. Shehata, N.; Sayed, E.T.; Abdelkareem, M.A. Recent progress in environmentally friendly geopolymers: A review. Sci. Total Environ. 2021, 762, 143166. [CrossRef] [PubMed]

13. Vlachakis, C.; Perry, M.; Biondi, L. Self-Sensing Alkali-Activated Materials: A Review. Minerals 2020, 10, 885. [CrossRef]

14. Lee, W.; van Deventer, J. The effects of inorganic salt contamination on the strength and durability of geopolymers. Colloids Surf. A Physicochem. Eng. Asp. 2002, 211, 115-126. [CrossRef] 
15. Alghamdi, H.; Nair, S.A.; Neithalath, N. Insights into material design, extrusion rheology, and properties of 3D-printable alkali-activated fly ash-based binders. Mater. Des. 2019, 167, 107634. [CrossRef]

16. Mermerdaş, K.; Manguri, S.; Nassani, D.E.; Oleiwi, S.M. Effect of aggregate properties on the mechanical and absorption characteristics of geopolymer mortar. Eng. Sci. Technol. Int. J. 2017, 20, 1642-1652. [CrossRef]

17. Embong, R.; Kusbiantoro, A.; Shafiq, N.; Nuruddin, M.F. Strength and microstructural properties of fly ash based geopolymer concrete containing high-calcium and water-absorptive aggregate. J. Clean. Prod. 2016, 112, 816-822. [CrossRef]

18. Azimi, E.A.; Abdullah, M.M.A.B.; Vizureanu, P.; Salleh, M.A.A.M.; Sandu, A.V.; Chaiprapa, J.; Yoriya, S.; Hussin, K.; Aziz, I.H. Strength Development and Elemental Distribution of Dolomite/Fly Ash Geopolymer Composite under Elevated Temperature. Materials 2020, 13, 1015. [CrossRef]

19. Aboulayt, A.; Riahi, M.; Touhami, M.O.; Hannache, H.; Gomina, M.; Moussa, R. Properties of metakaolin based geopolymer incorporating calcium carbonate. Adv. Powder Technol. 2017, 28, 2393-2401. [CrossRef]

20. Yip, C.K.; Provis, J.L.; Lukey, G.C.; van Deventer, J.S. Carbonate mineral addition to metakaolin-based geopolymers. Cem. Concr. Compos. 2008, 30, 979-985. [CrossRef]

21. Qian, J.; Song, M. Study on influence of limestone powder on the fresh and hardened properties of early age metakaolin based geopolymer. In Calcined Clays for Sustainable Concrete; RILEM Book series; Scrivener, K., Favier, A., Eds.; Springer: Lausanne, Switzerland, 2015; Volume 10, pp. 253-259.

22. Cwirzen, A.; Provis, J.L.; Penttala, V.; Habermehl-Cwirzen, K. The effect of limestone on sodium hydroxide-activated metakaolinbased geopolymers. Constr. Build. Mater. 2014, 66, 53-62. [CrossRef]

23. Perez-Cortes, P.; Escalante-Garcia, J.I. Alkali activated metakaolin with high limestone contents-Statistical modeling of strength and environmental and cost analyses. Cem. Concr. Compos. 2020, 106, 103450. [CrossRef]

24. Bayiha, B.N.; Billong, N.; Yamb, E.; Kaze, R.C.; Nzengwa, R. Effect of limestone dosages on some properties of geopolymer from thermally activated halloysite. Constr. Build. Mater. 2019, 217, 28-35. [CrossRef]

25. Rakhimova, N.R.; Rakhimov, R.; Morozov, V.P.; Gaifullin, A.R.; Potapova, L.I.; Gubaidullina, A.M.; Osin, Y. Marl-based geopolymers incorporated with limestone: A feasibility study. J. Non-Cryst. Solids 2018, 492, 1-10. [CrossRef]

26. Cohen, E.; Peled, A.; Bar-Nes, G. Dolomite-based quarry-dust as a substitute for fly-ash geopolymers and cement pastes. J. Clean Prod. 2019, 235, 910-919. [CrossRef]

27. Ortega-Zavala, D.E.; Santana-Carrillo, J.L.; Burciaga-Díaz, O.; Escalante-García, J.I. An initial study on alkali activated limestone binders. Cem. Concr. Res. 2019, 120, 267-278. [CrossRef]

28. Aizat, E.A.; Al Bakri, A.M.M.; Liew, Y.M.; Heah, C.Y. Chemical composition and strength of dolomite geopolymer compo-sites. AIP Conf. Proc. 2017, 1885, 020192.

29. Kumar, R.; Kumar, S.; Alex, T.C.; Singla, R. Mapping of calorimetric response for the geopolymerisation of mechanically activated fly ash. J. Therm. Anal. Calorim. 2018, 136, 1117-1133. [CrossRef]

30. Matsuoka, M.; Yokoyama, K.; Okura, K.; Murayama, N.; Ueda, M.; Naito, M. Synthesis of Geopolymers from Mechanically Activated Coal Fly Ash and Improvement of Their Mechanical Properties. Minerals 2019, 9, 791. [CrossRef]

31. Temuujin, J.; Williams, R.; van Riessen, A. Effect of mechanical activation of fly ash on the properties of geopolymer cured at ambient temperature. J. Mater. Process. Technol. 2009, 209, 5276-5280. [CrossRef]

32. Marjanović, N.; Komljenović, M.; Baščarević, Z.; Nikolic, V. Improving reactivity of fly ash and properties of ensuing geopolymers through mechanical activation. Constr. Build. Mater. 2014, 57, 151-162. [CrossRef]

33. Kato, K.; Xin, Y.; Hitomi, T.; Shirai, T. Surface modification of fly ash by mechano-chemical treatment. Ceram. Int. 2019, 45, 849-853. [CrossRef]

34. Fernández-Jiménez, A.; Garcia-Lodeiro, I.; Maltseva, O.; Palomo, A. Mechanical-Chemical Activation of Coal Fly Ashes: An Effective Way for Recycling and Make Cementitious Materials. Front. Mater. 2019, 6. [CrossRef]

35. Mucsi, G. Mechanical activation of power station fly ash by grinding-A review. Epitoanyag J. Silic. Based Compos. Mater. 2016, 68, 56-61. [CrossRef]

36. Nath, S.; Kumar, S. Role of particle fineness on engineering properties and microstructure of fly ash derived geopolymer. Constr. Build. Mater. 2020, 233, 117294. [CrossRef]

37. Kato, K.; Xin, Y.; Hitomi, T.; Shirai, T. Fabrication of solidified bodies by utilizing mechanochemically modified fly ash powder. J. Ceram. Soc. Jpn. 2020, 128, 224-228. [CrossRef]

38. Kalinkin, A.M.; Gurevich, B.I.; Myshenkov, M.S.; Chislov, M.V.; Kalinkina, E.V.; Zvereva, I.A.; Cherkezova-Zheleva, Z.; Paneva, D.; Petkova, V. Synthesis of Fly Ash-Based Geopolymers: Effect of Calcite Addition and Mechanical Activation. Minerals 2020, 10, 827. [CrossRef]

39. Lide, D.R. (Ed.) CRC Handbook of Chemistry and Physics, 89th ed.; CRC Press, Taylor and Francis Group: Boca Raton, FL, USA, $2008 ; 2736 p$.

40. Schumann, W. Handbook of Rocks, Minerals, and Gemstones; Houghton Mifflin Company: New York, NY, USA, 1993; 380p.

41. Mucsi, G.; Kumar, S.; Csőke, B.; Kumar, R.; Molnár, Z.; Rácz, Á.; Madai, F.; Debreczeni, Á. Control of geopolymer properties by grinding of land filled fly ash. Int. J. Miner. Process. 2015, 143, 50-58. [CrossRef]

42. Kumar, S.; Mucsi, G.; Kristály, F.; Pekker, P. Mechanical activation of fly ash and its influence on micro and nano-structural behaviour of resulting geopolymers. Adv. Powder Technol. 2017, 28, 805-813. [CrossRef] 
43. Bernal, S.A.; Provis, J.L.; Walkley, B.; Nicolas, R.S.; Gehman, J.D.; Brice, D.G.; Kilcullen, A.R.; Duxson, P.; Van Deventer, J.S. Gel nanostructure in alkali-activated binders based on slag and fly ash, and effects of accelerated carbonation. Cem. Concr. Res. 2013, 53, 127-144. [CrossRef]

44. Navrotsky, A. Energetic clues to pathways to biomineralization: Precursors, clusters, and nanoparticles. Proc. Natl. Acad. Sci. USA 2004, 101, 12096-12101. [CrossRef]

45. Lee, W.K.W.; Van Deventer, J.S.J. Use of Infrared Spectroscopy to Study Geopolymerization of Heterogeneous Amorphous Aluminosilicates. Langmuir 2003, 19, 8726-8734. [CrossRef]

46. Fernández-Jiménez, A.; Palomo, A. Mid-infrared spectroscopic studies of alkali-activated fly ash structure. Microporous Mesoporous Mater. 2005, 86, 207-214. [CrossRef]

47. Álvarez-Ayuso, E.; Querol, X.; Plana, F.; Alastuey, A.; Moreno, N.; Izquierdo, M.; Font, O.; Moreno, T.; Díez, S.; Vázquez, E.; et al. Environmental, physical and structural characterisation of geopolymer matrixes synthesised from coal (co-)combustion fly ashes. J. Hazard. Mater. 2008, 154, 175-183. [CrossRef] [PubMed]

48. White, W.B. The carbonate minerals. In The Infrared Spectra of Minerals; Farmer, W.C., Ed.; Mineralogical Society: London, UK, 1974; pp. 227-284.

49. Provis, J.L.; Rose, V.; Bernal, S.A.; van Deventer, J.S.J. High-Resolution Nanoprobe X-ray Fluorescence Characterization of Heterogeneous Calcium and Heavy Metal Distributions in Alkali-Activated Fly Ash. Langmuir 2009, 25, 11897-11904. [CrossRef] [PubMed]

50. Lee, W.; van Deventer, J. The effect of ionic contaminants on the early-age properties of alkali-activated fly ash-based cements. Cem. Concr. Res. 2002, 32, 577-584. [CrossRef] 